\title{
Constance Cagnat-Debœuf, De l'art de la mystification dans Le Spleen de Paris: une lecture de «La corde»
}

\section{Maria Emanuela Raffi}

\section{(2) OpenEdition}

1 Journals

\section{Edizione digitale}

URL: https://journals.openedition.org/studifrancesi/3161

DOI: 10.4000/studifrancesi.3161

ISSN: 2421-5856

\section{Editore}

Rosenberg \& Sellier

\section{Edizione cartacea}

Data di pubblicazione: 1 juillet 2013

Paginazione: 478

ISSN: 0039-2944

\section{Notizia bibliografica digitale}

Maria Emanuela Raffi, «Constance Cagnat-Debœuf, De l'art de la mystification dans Le Spleen de Paris: une lecture de «La corde»», Studi Francesi [Online], 170 (LVII | II) | 2013, online dal 30 novembre 2015, consultato il 02 février 2023. URL: http://journals.openedition.org/studifrancesi/3161 ; DOI: https:// doi.org/10.4000/studifrancesi.3161

Questo documento è stato generato automaticamente il 2 février 2023.

\section{(c) 9 (1) $\Theta$}

Creative Commons - Attribuzione - Non commerciale - Non opere derivate 4.0 Internazionale - CC BYNC-ND 4.0

https://creativecommons.org/licenses/by-nc-nd/4.0/ 


\title{
Constance Cagnat-Debœuf, De l'art de la mystification dans Le Spleen de Paris: une lecture de «La corde»
}

\author{
Maria Emanuela Raffi
}

\section{NOTIZIA}

CONSTANCE CAGNAT-DEBGEU, De l'art de la mystification dans Le Spleen de Paris: une lecture de «La corde», «Romantisme», 157, septembre 2012, pp. 101-115.

1 Il tentativo di spiegare il mistero legato al poema in prosa di Baudelaire «La corde» è ciò che muove anzitutto la lettura dell'A., a partire dalla dedica a Manet, al quale è affidata nel testo la narrazione del terribile episodio del suicidio del suo giovane modello. I segni dell'indifferenza e della scarsa perspicacia del pittore nei confronti del bambino appaiono evidenti; i piccoli furti di sucre e liqueurs vengono spiegati dall'A. come furti di quel «sucre de Saturne» e dell'«extrait de Saturne» utilizzati in pittura per produrre la biacca di piombo. La tristezza del bambino non è dunque vaga $\mathrm{e}$ inspiegabile come appare nel racconto del pittore, ma prodotta dal saturnismo indotto dai materiali che si trova ad utilizzare e a maneggiare. Tuttavia il senso del racconto baudelairiano non sta in questa denuncia, ma nella denuncia, o nella celebrazione, della mistificazione in arte. A partire dalla corrispondenza che Baudelaire attua, secondo l'A., fra gli elementi del racconto e una suggestiva e ricca serie di proverbi, dalla disillusione sull'apparente amore materno da parte della madre del piccolo impiccato e sulla generosità dei vicini, si realizza anche una corrispondenza più profonda fra gli scritti, come questo, di Baudelaire, che presentano un enigma da decifrare e i quadri di Manet, anch'essi interpretabili come dei «tableaux à secrets». 